\title{
Torsional irregularity in multi-story structures
}

\author{
Günay Özmen · Konuralp Girgin · Yavuz Durgun
}

Received: 14 February 2014/ Accepted: 4 September 2014/Published online: 17 September 2014

(C) The Author(s) 2014. This article is published with open access at Springerlink.com

\begin{abstract}
The purpose of this study is first to determine the conditions for excessive torsional irregularity and then to discuss the validity of code provisions. A parametric investigation is performed on six groups of typical structures with varying shear wall positions, story, and axis numbers. It is found that torsional irregularity coefficients increase as the story numbers decrease, i.e., maximum irregularity coefficients occur for single-story structures. They reach maximum values when the asymmetrical shear walls are placed as close as possible to the centers of mass. However, the results obtained for floor rotations are quite contradictory. A new provisional definition for torsional irregularity coefficient based on floor rotations is proposed.
\end{abstract}

Keywords Earthquake regulations - Torsional irregularity $\cdot$ Parametric investigation $\cdot$ Floor rotations

\section{Introduction}

Earthquake field investigations repeatedly confirm that irregular structures suffer more damage than their regular counterparts. Torsional irregularity is one of the most important factors, which causes severe damage (even collapse) for the structures. A large number of studies exist which investigate various aspects of torsional irregularity including geometric asymmetry (Duan and Chandler 1997; Ozmen 2002; Demir et al. 2010; stiffness distribution Ozmen 2002, 2004; Tezcan and Alhan 2001), analysis methods such as pushover and non-linear dynamic analyses

G. Özmen · K. Girgin $(\bowtie) \cdot$ Y. Durgun

Civil Engineering Faculty, Istanbul Technical University, Maslak, Istanbul 34469, Turkey

e-mail: girgink@itu.edu.tr etc. (e.g. Penelis and Kappos 2002; Dogangun and Livaoglu 2006; Jinjie et al. 2008; Mahdi and Gharaie 2011), comparison and discussion of code provisions (Cosenza et al. 2000; Bosco et al. 2004; Zheng et al. 2004; Ozhendekci and Polat 2008), and both experimental and analytical studies by Jeong and Elnashai (2004, 2006).

Regarding the torsional irregularities, most of the codes have similar provisions essentially based on principles of the well-known standards of IBC06 (2006), UBC97 (1997), and ASCE7-10 (2010). A certain number of studies are devoted to the discussion and interpretation of the provisions in UBC97, IBC06 (2006), and other seismic codes.

Duan and Chandler (1997) proposed an optimized procedure for seismic design of torsionally unbalanced structures. Ozmen (2002) investigated geometric and structural aspects of torsional irregularity according to (Turkish Earthquake Code 2007). Demir et al. (2010) investigated torsional irregularity factors which effect multi story shear wall-frame systems according to TEC2007. Six type structures which have different story numbers, plan views, and shear wall locations were analyzed. Ozmen (2004) determined the shear wall positions which cause excessive torsional irregularity according to TEC2007 and discussed the related code provisions. Tezcan and Alhan (2001) proposed an increase in the calculated eccentricity in order to ensure an added and inherent safety for the flexible side elements. Penelis and Kappos (2002) presented a methodology for modeling the inelastic torsional response of buildings in nonlinear static (pushover) analysis, aiming to reproduce the results of inelastic dynamic time history analysis. Dogangun and Livaoglu (2006) examined the differences in results from equivalent seismic load method, mode-superposition method, and analysis method in time domain. They presented some recommendations related to the usage of seismic analysis methods. Jinjie et al. (2008) 
developed a torsion angle capacity spectrum method for the performance-based seismic evaluation of irregular framed structures. Mahdi and Gharaie (2011) evaluated the seismic behavior of three intermediate moment-resisting concrete space frames with unsymmetrical plan using pushover analysis. Cosenza et al. (2000) compared most of the results existing in the literature, suggested proposals of modification and underlined the importance of further studies in order to evaluate a condition of minimum torsional stiffness.

Bosco et al. (2004) described a study devoted to define the application limits of an approximated design method about non-regularly asymmetric systems. They anticipated that to define clear limits is possible in seismic codes for the simplified approaches on irregular structures. Zheng et al. (2004) studied the criterion and relative regulations for torsional irregularity in UBC97 and Eurocode 8 (2004). The results through the codes were analyzed and compared from the theoretical and practical aspects. Ozhendekci and Polat (2008) introduced a parameter $Q$ which is a ratio of the effective modal masses to be used to define the torsional irregularity of buildings. The proposed ratio in ASCE 7-05 (2005) for the definition of the torsional irregularities is compared with the modified $Q$ ratio. Jeong and Elnashai (2004) proposed a layering technique, termed planar decomposition which furnishes detailed information on the demand and capacity of critical members. Jeong and Elnashai (2006) described a local damage index that is sensitive to out-of-plane responses and presented a method to combine local damage indices.

Torsional irregularity which is recognized in most of the seismic design codes varies depending on a number of factors including plan geometry, dimensions and positions of structural elements, and story numbers. The purpose of this study is first to determine the conditions for excessive torsional irregularity and then to discuss the validity of code provisions. In order to achieve this aim, a parametric investigation is performed for six groups of typical structures by considering different shear wall positions, story, and axis numbers. Number of axes in the typical structure groups is varied between 5,6 , and 7 while story numbers are chosen as 1, 2, 4, 6, 8 and 10. All the structures are chosen as symmetrical in plan with respect to horizontal axis $X$. Hence, the behavior of structures will be examined only for the lateral loading in $Y$ direction.

\section{Code provisions for torsional irregularity}

The provisions of ASCE 7-10 (2010) regarding the torsional irregularities are summarized in the following.

In Clause 12.8.4.3 of the code, the accidental lateral load eccentricities of $\pm 5 \%$ are amplified by the factor
$A_{\mathrm{x}}=\left(\frac{\delta_{\mathrm{max}}}{1.2 \delta_{\mathrm{avg}}}\right)^{2}$,

where $\delta_{\max }$ and $\delta_{\text {avg }}$ are the maximum displacement at Level $x$ and the average of the displacements at the extreme points of the structure at Level $x$, respectively, computed by assuming $A_{\mathrm{x}}=1$. Extreme and average displacements at Level $x$ are shown in Fig. 1. The torsional amplification factor $\left(A_{\mathrm{x}}\right)$ shall not be less than 1 and is not required to exceed 3.0. These provisions may be expressed alternatively as follows:

Torsional irregularity coefficient $\eta_{\mathrm{t}}$ is defined by

$\eta_{\mathrm{t}}=\frac{\delta_{\max }}{\delta_{\mathrm{avg}}}$

Then

(a) If $\eta_{\mathrm{t}} \leq 1.2$ then torsional irregularity does not exist, i.e., $A_{\mathrm{x}}=1$;

(b) If $1.2<\eta_{\mathrm{t}} \leq 2.083$ then torsional irregularity exists and eccentricity amplification factor is computed by

$A_{\mathrm{x}}=\left(\frac{\eta_{\mathrm{t}}}{1.2}\right)^{2}$

(c) If $\eta_{\mathrm{t}}>2.083$ then $\eta_{\mathrm{t}}=2.083\left(A_{\mathrm{x}}=3.0\right)$.

In the following investigations, the torsional irregularity coefficient $\eta_{\mathrm{t}}$ is considered as the main parameter.

\section{Typical structures}

Six groups typical structures (A, B, C, D, E, and F), which are selected to carry out the parametric study, are chosen as multi-story buildings composed of frames and walls. The typical structures are chosen as having asymmetric walls in a rectangular plan. All of them are composed of $3.50 \times 5.00 \mathrm{~m}^{2}$ modules and have six axes in the direction

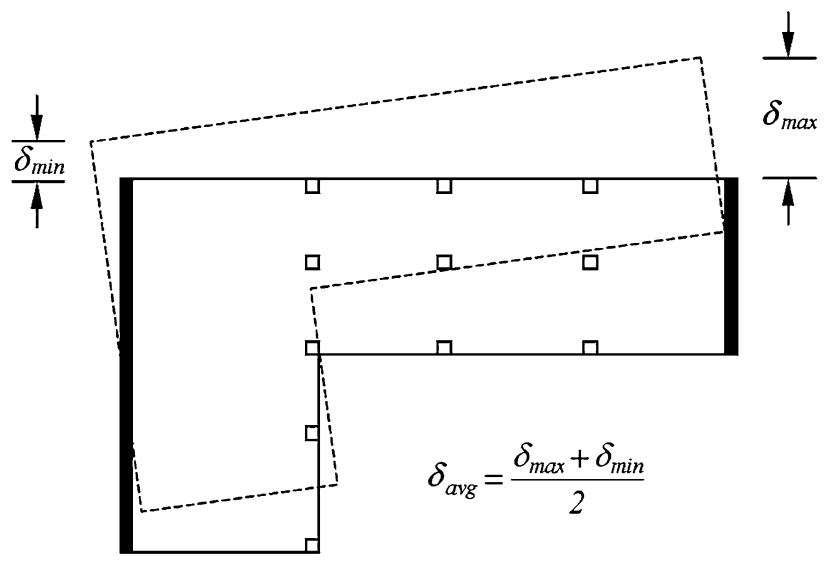

Fig. 1 Extreme and average displacements 
$Y$. Schematic floor plans of typical structures are shown in Fig. 2. As can be seen in the figure, all the typical structures are symmetrical about axis $X$. For the typical structure A, the shear walls in direction $Y$ are on the left edge of the floor plan. In the typical structures $\mathrm{C}, \mathrm{E}$; the centers of gravity of walls were shifted by 1 and 2 modules respect to A in direction $X$. As for $\mathrm{D}, \mathrm{F}$; the centers of gravity of walls were shifted by 1 and 2 modules respect to B. All the wall thicknesses are $25 \mathrm{~cm}$ and beam cross sections are $25 \times 50 \mathrm{~cm}^{2}$. Column dimensions vary between $30 \times 30 \mathrm{~cm}^{2}$ and $45 \times 70 \mathrm{~cm}^{2}$. Further details about column dimensions for typical structures can be found in the original technical report by Ozmen et al. (2012). Story heights for all the typical structures are $4.00 \mathrm{~m}$ for lowermost story and $3.00 \mathrm{~m}$ for upper stories.

The parametric investigations of this study are independent from the magnitude of seismic forces affecting the structure. However, since it is aimed to obtain realistic results, the dimensions of the structural elements are determined using a preliminary design process. Seismic parameters used in the analyses and designs of typical structures are as follows:

MCE Spectral Acceleration Parameters $S M S=0.75 \mathrm{~g}$, $S M 1=0.33 \mathrm{~g}$,

Site Coefficients $F a=1, F v=1$,

Importance Factor $I=1$,

Response Modification Coefficient $R=7$.

Fundamental period in direction $Y$ and corresponding equivalent lateral forces are computed only for typical structure type A. Lateral loads of same magnitude are used in the analyses of other types in order to obtain a sound comparison. In ASCE7-10 (2010), the limiting period is given as

$T_{\mathrm{a}}=C_{\mathrm{t}} h_{\mathrm{n}}^{\mathrm{x}}$

where $h_{\mathrm{n}}$ is the structural height, $C_{\mathrm{t}}=0.0488$, and $x=0.75$ for the structures under consideration. For most of the typical structures, the limiting period is found to be lower than that obtained by the modal analysis. Hence in computing equivalent lateral forces the limiting period is used.

It is assumed that centers of gravity of stories are at the geometric centers of floor plans. Since all the typical structures are symmetrical with respect to axes $X$, investigations will be carried out only for loadings in direction $Y$. In lateral load analyses, the unfavorable accidental eccentricity of $+5 \%$ will be considered.

Structure groups are derived from typical structure types by changing number of axes. Schematic floor plans of typical structure type A are derived with 5, 6 and 7 axes in $Y$ direction (Fig. 3) to analyze the torsional irregularity. Floor plans of typical structure types B, C, D,
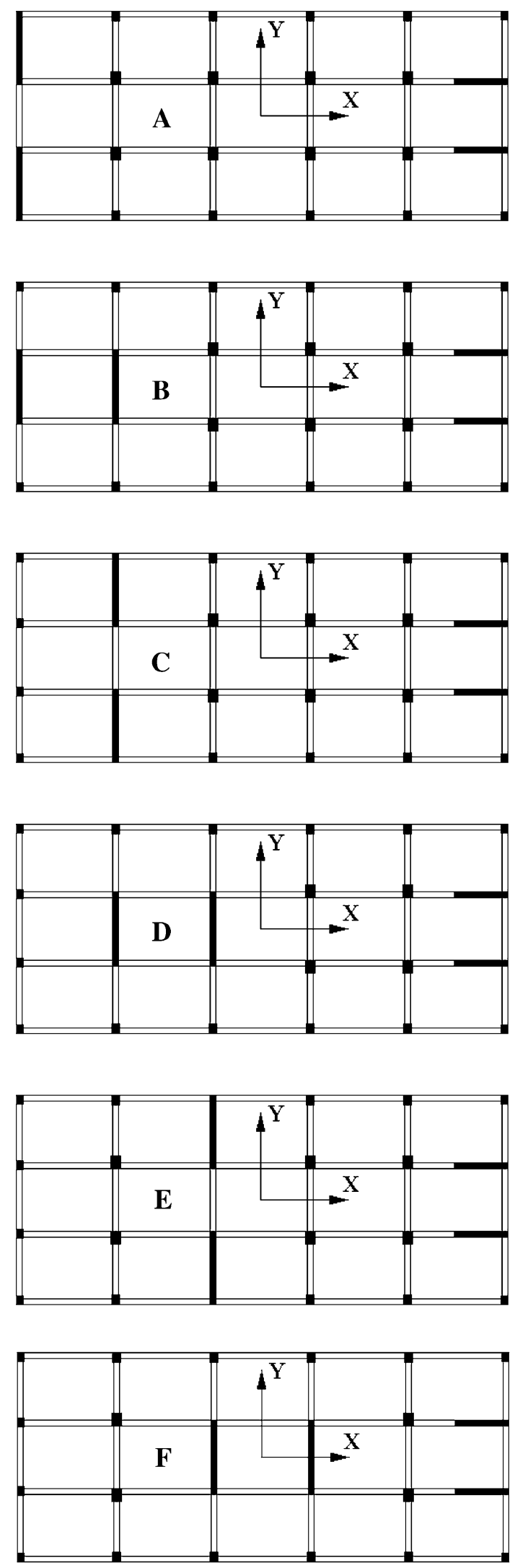

Fig. 2 Schematic floor plans of typical structures with 6 axes 

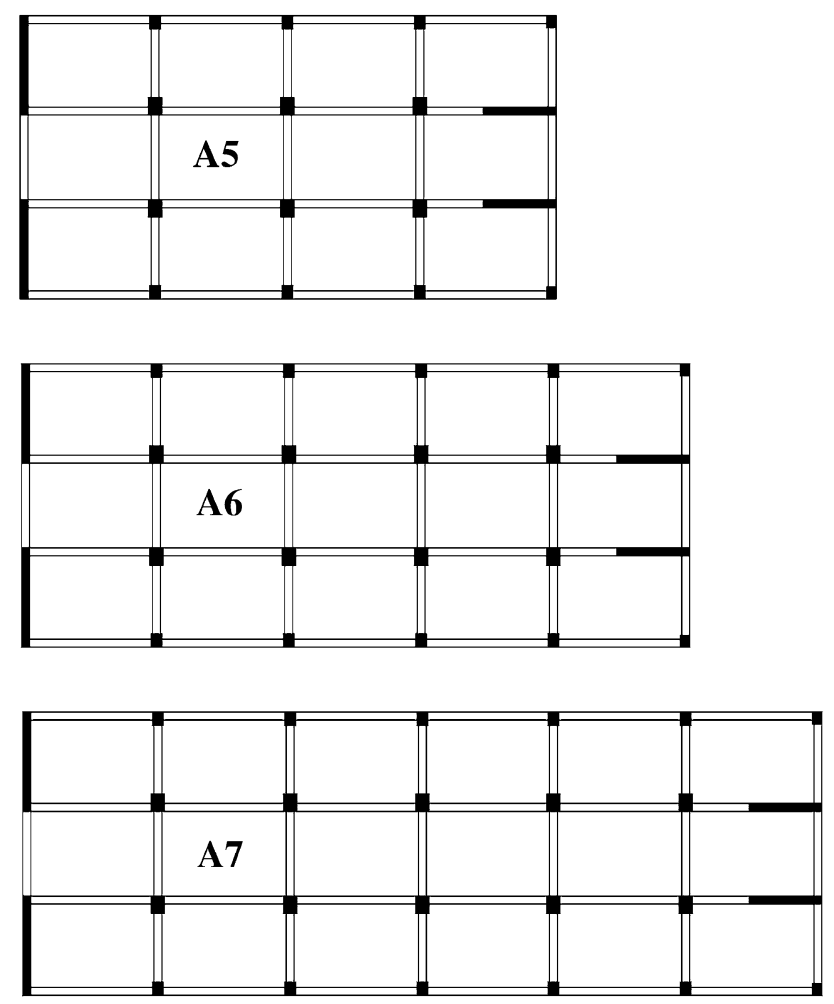

Fig. 3 Schematic floor plans of structure type A with 5, 6, and 7 axes

$\mathrm{E}$, and $\mathrm{F}$ with the same number of axes are organized similarly as well.

\section{Investigation of torsional irregularity coefficient}

In this section, the structure groups with 5, 6, and 7 axes will be considered, the related maximum torsional irregularity coefficients will be determined and the results will be discussed. First, lateral analysis of a structure group with a definite axis number is executed for 10-story type A structure, then the results of all the structures in that group will be presented in Tables.

The details of the seismic analyses are not shown herein for the sake of brevity. The variation of maximum torsional irregularity coefficient and the results will be discussed after the inspection of all structure types. Bold numerals at each row of regarding tables indicate the maximum values. Interpretation of the results will be presented in a separate section.

Structure group with five axes

In this section, seismic analyses of structure group with five axes are performed. Since the types E and F do not give unfavorable results of torsional irregularity, seismic
Table 1 Story displacements and torsional irregularity coefficients for 10-story Type A structure

\begin{tabular}{llllll}
\hline $\begin{array}{l}\text { Story } \\
\text { no. }\end{array}$ & $\begin{array}{l}\text { Lateral load } \\
(\mathrm{kN})\end{array}$ & $\begin{array}{l}\delta_{\min } \\
(\mathrm{cm})\end{array}$ & $\begin{array}{l}\delta_{\text {avg }} \\
(\mathrm{cm})\end{array}$ & $\begin{array}{l}\delta_{\max } \\
(\mathrm{cm})\end{array}$ & $\begin{array}{l}\eta_{\mathrm{t}} \\
\left(\delta_{\text {max }} / \delta_{\text {avg }}\right)\end{array}$ \\
\hline 10 & 150 & 1.971 & 4.177 & 6.382 & 1.528 \\
9 & 178 & 1.769 & 3.915 & 6.060 & 1.548 \\
8 & 158 & 1.555 & 3.573 & 5.592 & 1.565 \\
7 & 138 & 1.331 & 3.180 & 5.029 & 1.581 \\
6 & 118 & 1.097 & 2.726 & 4.354 & 1.597 \\
5 & 98 & 0.861 & 2.247 & 3.633 & 1.617 \\
4 & 78 & 0.629 & 1.739 & 2.850 & 1.638 \\
3 & 59 & 0.414 & 1.252 & 2.089 & 1.669 \\
2 & 40 & 0.227 & 0.770 & 1.312 & 1.705 \\
1 & 29 & 0.085 & 0.346 & 0.608 & 1.756 \\
& & & & Max & 1.756 \\
\hline
\end{tabular}

Table 2 Maximum torsional irregularity coefficients for structures with 5 axes

\begin{tabular}{lllll}
\hline \multirow{2}{*}{ Number of stories } & \multicolumn{4}{l}{ Structure type } \\
\cline { 2 - 5 } & $\mathrm{A}$ & $\mathrm{B}$ & $\mathrm{C}$ & $\mathrm{D}$ \\
\hline 1 & 1.918 & 2.076 & $\mathbf{2 . 5 5 1}$ & 2.487 \\
2 & 1.891 & 2.024 & $\mathbf{2 . 4 2 0}$ & 2.262 \\
4 & 1.855 & 1.962 & $\mathbf{2 . 2 7 9}$ & 2.073 \\
6 & 1.824 & 1.917 & $\mathbf{2 . 1 6 3}$ & 1.963 \\
8 & 1.790 & 1.873 & $\mathbf{2 . 0 5 6}$ & 1.875 \\
10 & 1.756 & 1.830 & $\mathbf{1 . 9 5 5}$ & 1.804 \\
\hline
\end{tabular}

analyses for these types are not included in the investigation. Story numbers of types A, B, C, and D are varied as 1 , $2,4,6,8$, and 10 . Thus, the number of the investigated structures for this group is 24 .

\section{0-story Type A structure}

Lateral loads, minimum, average and maximum story displacements $\left(\delta_{\min }, \delta_{\text {avg }}\right.$ and $\left.\delta_{\max }\right)$ are shown in Table 1 . It must be noted that maximum torsional irregularity coefficient occurs at 1 st story.

\section{All structure types}

Similar analyses are performed for types B, C, and D and torsional irregularity coefficients are computed. As have been mentioned above, lateral loads used in these analyses are the same as those used for structures type A. Maximum torsional irregularity coefficients for all types with five axes are shown in Table 2. It is seen that this coefficient is maximum for Type $\mathrm{C}$ in all stories. 
Table 3 Story displacements and torsional irregularity coefficients for 10-story Type A structure

\begin{tabular}{llllll}
\hline $\begin{array}{l}\text { Story } \\
\text { no. }\end{array}$ & $\begin{array}{l}\text { Lateral load } \\
(\mathrm{kN})\end{array}$ & $\begin{array}{l}\delta_{\min } \\
(\mathrm{cm})\end{array}$ & $\begin{array}{l}\delta_{\text {avg }} \\
(\mathrm{cm})\end{array}$ & $\begin{array}{l}\delta_{\max } \\
(\mathrm{cm})\end{array}$ & $\begin{array}{l}\eta_{\mathrm{t}} \\
\left(\delta_{\text {max }} / \delta_{\text {avg }}\right)\end{array}$ \\
\hline 10 & 179 & 2.083 & 4.506 & 6.929 & 1.538 \\
9 & 233 & 1.872 & 4.229 & 6.587 & 1.557 \\
8 & 206 & 1.647 & 3.859 & 6.071 & 1.573 \\
7 & 180 & 1.411 & 3.435 & 5.459 & 1.589 \\
6 & 154 & 1.165 & 2.943 & 4.721 & 1.604 \\
5 & 128 & 0.916 & 2.426 & 3.937 & 1.623 \\
4 & 102 & 0.670 & 1.875 & 3.081 & 1.643 \\
3 & 77 & 0.442 & 1.351 & 2.260 & 1.673 \\
2 & 53 & 0.243 & 0.831 & 1.419 & 1.708 \\
1 & 35 & 0.091 & 0.375 & 0.659 & 1.757 \\
& & & & Max & 1.757 \\
\hline
\end{tabular}

Structure group with six axes

Seismic analysis of structure group with six axes will be executed and the maximum torsional irregularity coefficients will be determined. Story numbers of types A, B, C, $\mathrm{D}, \mathrm{E}$, and $\mathrm{F}$ are varied as $1,2,4,6,8$, and 10 . Thus, the number of the investigated structures for this group is 36 .

\section{0-story Type A structure}

Lateral loads, $\delta_{\min }, \delta_{\text {avg, }}$ and $\delta_{\max }$ displacements are given in Table 3. Here again, maximum torsional irregularity coefficient occurs at 1 st story.

\section{All structure types}

Maximum torsional irregularity coefficients for six axes are displayed in Table 4 and maximum coefficients in all story numbers occur in Type E.

Structure group with seven axes

The structure group with seven axes will be handled and the number of the structures in this group is 36. Story numbers of types A, B, C, D, E, and F are varied as 1, 2, 4, 6,8 , and 10. In the following, first lateral analysis results of 10-story type A structure, then the results of all the structures in this group will be presented.

\section{0-story Type A structure}

Lateral loads and displacements are given in Table 5. Here again, maximum irregularity coefficient occurs at 1 st story.
Table 4 Maximum torsional irregularity coefficients for structures with 6 axes

\begin{tabular}{lllllll}
\hline \multirow{2}{*}{ Number of stories } & \multicolumn{6}{l}{ Structure type } \\
\cline { 2 - 7 } & $\mathrm{A}$ & $\mathrm{B}$ & $\mathrm{C}$ & $\mathrm{D}$ & $\mathrm{E}$ & $\mathrm{F}$ \\
\hline 1 & 1.924 & 2.111 & 2.394 & 2.565 & $\mathbf{3 . 1 6 4}$ & 1.754 \\
2 & 1.898 & 2.022 & 2.309 & 2.403 & $\mathbf{2 . 7 6 7}$ & 1.524 \\
4 & 1.862 & 1.967 & 2.201 & 2.240 & $\mathbf{2 . 4 0 9}$ & 1.498 \\
6 & 1.831 & 1.925 & 2.112 & 2.128 & $\mathbf{2 . 1 8 0}$ & 1.473 \\
8 & 1.794 & 1.877 & 1.996 & 2.016 & $\mathbf{2 . 0 1 9}$ & 1.452 \\
10 & 1.757 & 1.837 & 1.887 & 1.925 & $\mathbf{1 . 9 2 7}$ & 1.448 \\
\hline
\end{tabular}

Table 5 Story displacements and torsional irregularity coefficients for 10-story Type A structure

\begin{tabular}{llllll}
\hline $\begin{array}{l}\text { Story } \\
\text { no. }\end{array}$ & $\begin{array}{l}\text { Lateral load } \\
(\mathrm{kN})\end{array}$ & $\begin{array}{l}\delta_{\text {min }} \\
(\mathrm{cm})\end{array}$ & $\begin{array}{l}\delta_{\text {avg }} \\
(\mathrm{cm})\end{array}$ & $\begin{array}{l}\delta_{\max } \\
(\mathrm{cm})\end{array}$ & $\begin{array}{l}\eta_{t} \\
\left(\delta_{\text {max }} / \delta_{\text {avg }}\right)\end{array}$ \\
\hline 10 & 209 & 2.094 & 4.528 & 6.961 & 1.537 \\
9 & 271 & 1.882 & 4.248 & 6.613 & 1.557 \\
8 & 240 & 1.657 & 3.869 & 6.080 & 1.572 \\
7 & 210 & 1.422 & 3.442 & 5.463 & 1.587 \\
6 & 179 & 1.175 & 2.946 & 4.717 & 1.601 \\
5 & 149 & 0.925 & 2.427 & 3.929 & 1.619 \\
4 & 119 & 0.677 & 1.873 & 3.068 & 1.638 \\
3 & 90 & 0.448 & 1.350 & 2.251 & 1.668 \\
2 & 62 & 0.247 & 0.830 & 1.414 & 1.703 \\
1 & 40 & 0.093 & 0.375 & 0.657 & 1.752 \\
& & & & Max & 1.752 \\
\hline
\end{tabular}

Table 6 Maximum torsional irregularity coefficients for structures with 7 axes

\begin{tabular}{lllllll}
\hline \multirow{2}{*}{ Number of stories } & \multicolumn{6}{l}{ Structure type } \\
\cline { 2 - 7 } & $\mathrm{A}$ & $\mathrm{B}$ & $\mathrm{C}$ & $\mathrm{D}$ & $\mathrm{E}$ & $\mathrm{F}$ \\
\hline 1 & 1.925 & 2.050 & 2.295 & 2.475 & $\mathbf{2 . 9 5 4}$ & 2.793 \\
2 & 1.895 & 2.012 & 2.230 & 2.363 & $\mathbf{2 . 7 1 6}$ & 2.452 \\
4 & 1.863 & 1.959 & 2.136 & 2.228 & $\mathbf{2 . 4 4 3}$ & 2.171 \\
6 & 1.831 & 1.919 & 2.061 & 2.131 & $\mathbf{2 . 2 5 6}$ & 2.013 \\
8 & 1.791 & 1.868 & 1.971 & 2.023 & $\mathbf{2 . 0 7 3}$ & 1.871 \\
10 & 1.752 & 1.828 & 1.888 & 1.929 & $\mathbf{1 . 9 3 1}$ & 1.770 \\
\hline
\end{tabular}

\section{All structure types}

For types B, C, D, E, and F with seven axes and torsional irregularity coefficients are computed. Maximum torsional irregularity coefficients for all types with seven axes are shown in Table 6. Here again, it is seen that they occur for Type $\mathrm{E}$ for all story numbers. 
Evaluation of torsional irregularity coefficient

In the preceding sections, seismic analyses of 96 structures with varying story numbers and shear wall positions have been performed. Maximum irregularity coefficients in Tables 2, 4, and 6 are represented graphically in Figs. 4, 5, and 6 , respectively. It is observed that

- Maximum irregularity for all types occurs for singlestory ones

- Maximum irregularity for all story numbers occurs when the asymmetric shear walls are placed as close as possible to the centers of mass.

40 of the investigated 96 structures (42\%) are subjected to excessive torsional irregularity. According to the code, these structures will be designed as having an irregularity coefficient of $\eta_{\mathrm{t}}=2.083\left(A_{\mathrm{x}}=3.00\right)$, Jeong and Elnashai (2006). This situation may be considered as being quite peculiar.

The wall positions standing for the maximum $\eta_{\mathrm{t}}$ values are quite unexpected since they correspond to almost symmetrical arrangements. It is also observed in the preceding investigations that floor rotation angles are somewhat greater for the structures with walls near the floor edges as well as structures with higher number of stories. It is believed that floor rotation angles $\theta$ reflect the torsional behavior of the structures more realistically. Therefore, floor rotations of the structures should be investigated in detail. In the following, floor rotation angles will be examined and compared with the concerned torsional irregularity coefficients.

\section{Discussion on the torsional irregularity coefficients}

According to the Table 4, maximum torsional irregularity coefficient occurs in one-story structures. For this case, two types of six-axes structures (A, E) are typically chosen to represent excessive torsional behavior. The detailed information about these structures is displayed in Table 7. The locations of center of mass and rigidity are calculated and given in Fig. 7. The following results obtained by comparing the torsional behavior for $\mathrm{A}$ and $\mathrm{E}$ types of structures:

(a) As the distances between the centers of mass and rigidity decreases, torsional irregularity coefficient increases on the contrary. The structure becomes vulnerable to the torsion since the torsional rigidity of structure decreases.

(b) As the distances between the center of mass and rigidity increases, torsional irregularity coefficient decreases on the contrary. This case results from increasing torsional rigidity of structure.

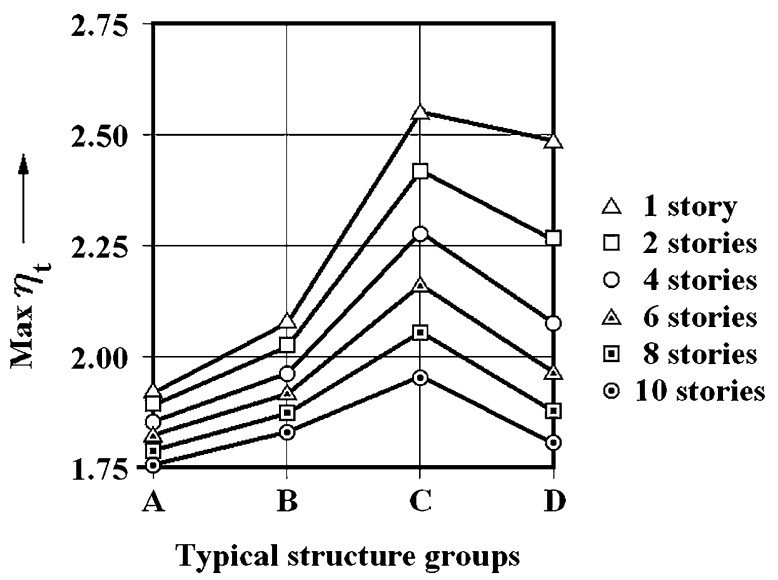

Fig. 4 Variation of maximum irregularity coefficient for structures with 5 axes

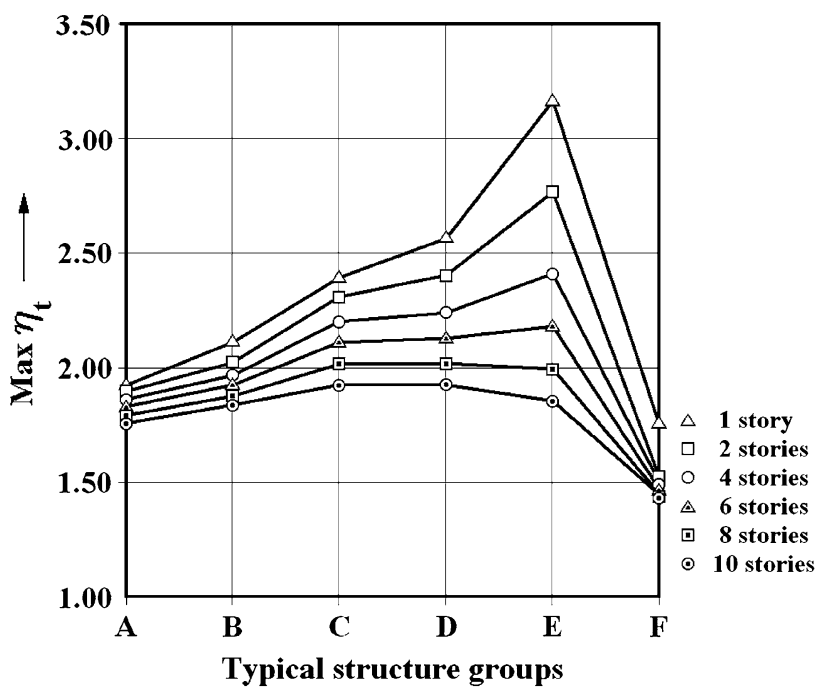

Fig. 5 Variation of maximum irregularity coefficient for structures with 6 axes

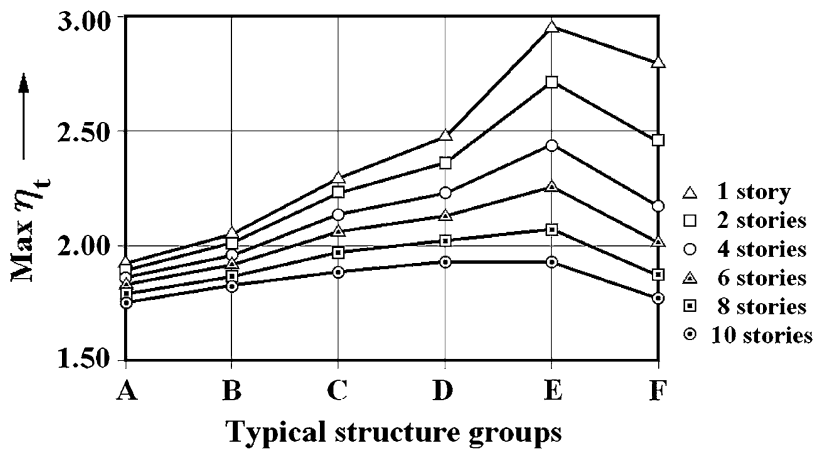

Fig. 6 Variation of maximum irregularity coefficient for structures with 7 axes 
Table 7 Detailed information for one-story structures

\begin{tabular}{llllllll}
\hline $\begin{array}{l}\text { Type of } \\
\text { structure }\end{array}$ & $\begin{array}{l}\text { Periods } \\
T_{\mathrm{y}}[\mathrm{s}]\end{array}$ & $\begin{array}{l}\text { Earthquake } \\
\text { forces } E_{\mathrm{y}}[\mathrm{kN}]\end{array}$ & $\begin{array}{l}\text { Torsional rigidity } \\
{[\mathrm{kNm}]}\end{array}$ & $\delta_{\max }[\mathrm{m}]$ & $\delta_{\text {avg }}[\mathrm{m}]$ & $\begin{array}{l}\text { Torsional irregularity } \\
\text { coefficient } \eta_{\mathrm{t}}\end{array}$ & $\begin{array}{l}\text { Rigid floor rotation } \\
10^{3} \times \theta^{(\mathrm{radian})}\end{array}$ \\
\hline $\mathrm{A}$ & 0.138 & 236.43 & $29,642,664.50$ & 0.002580 & 0.001341 & 1.924 & 0.0990 \\
$\mathrm{E}$ & 0.111 & 236.43 & $12,449,907.02$ & 0.001120 & 0.000354 & 3.164 & 0.0610 \\
\hline
\end{tabular}

Fig. 7 Center of mass (CM) and center of rigidity (CR) for one-story structures
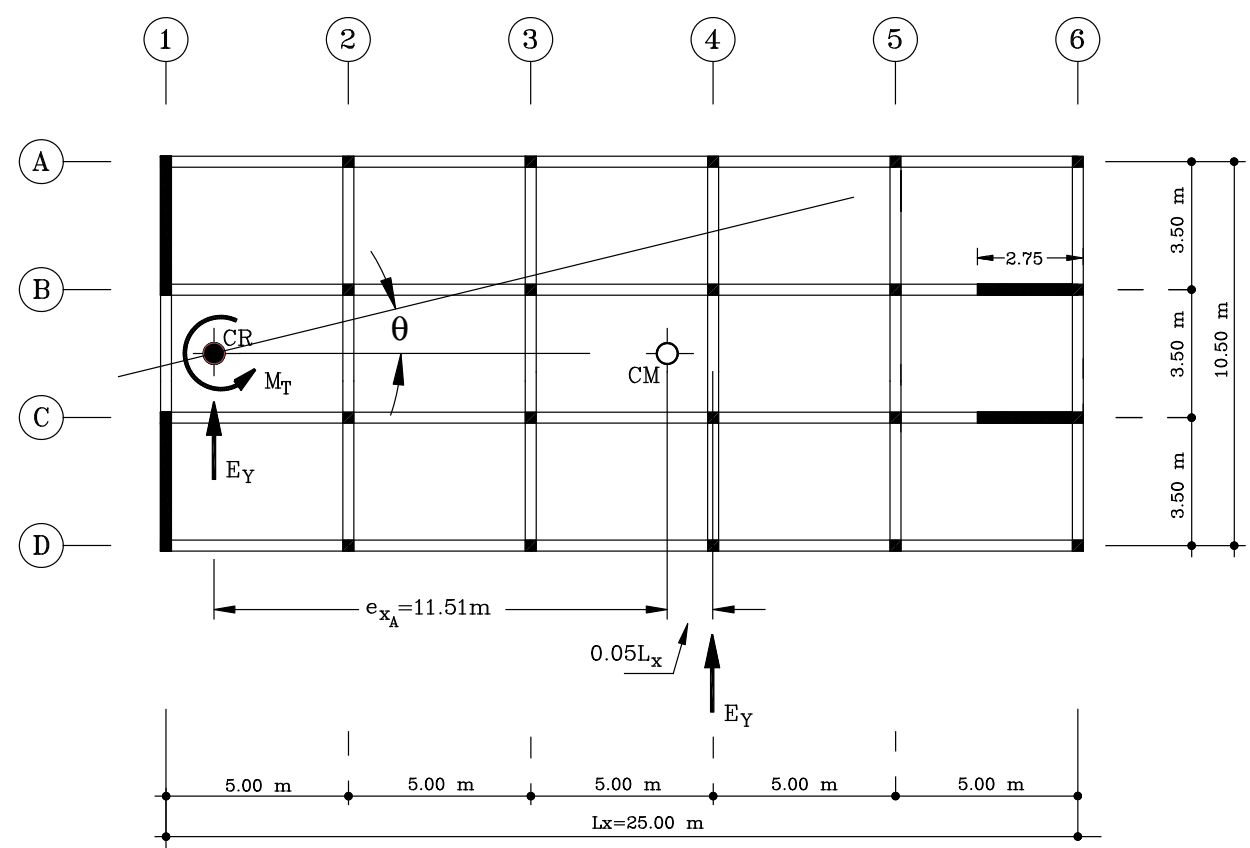

TYPE A

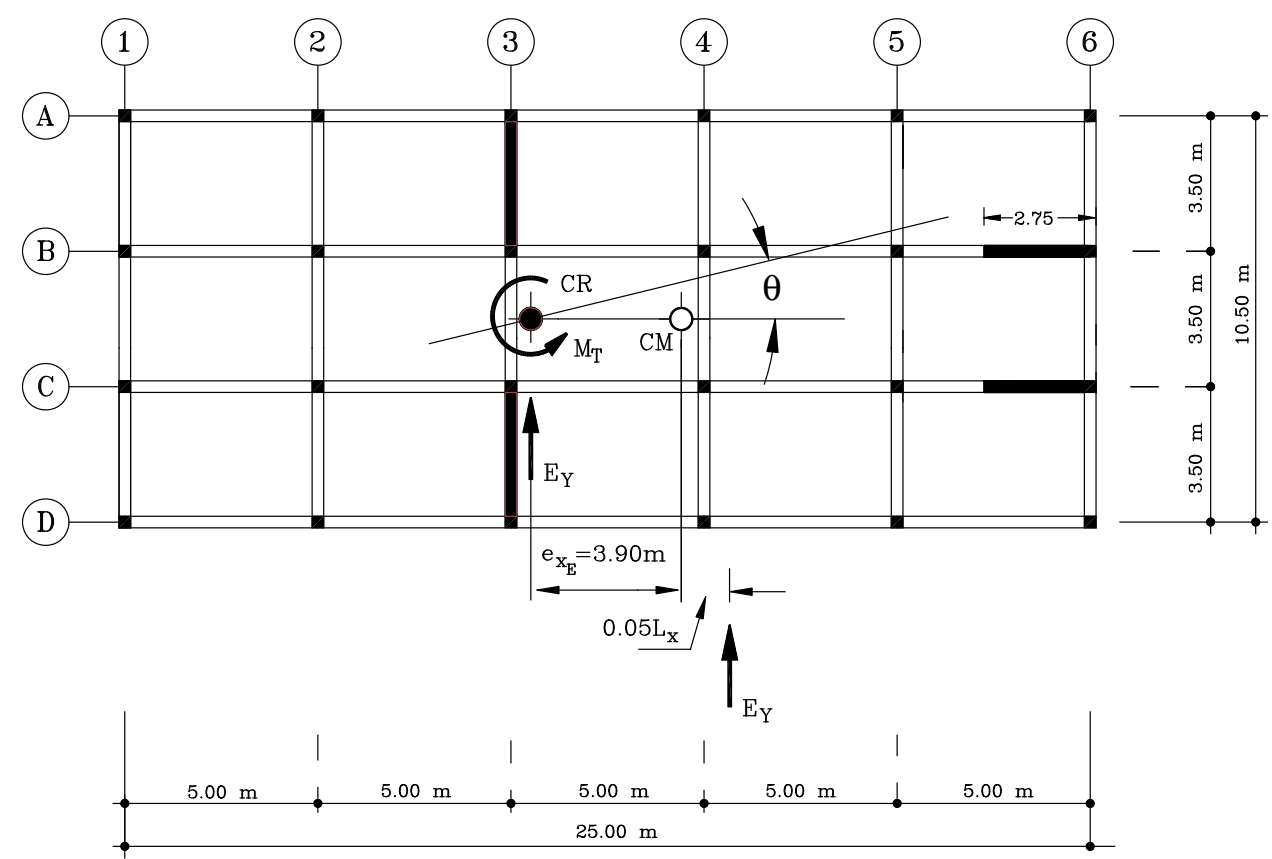

TYPE E 


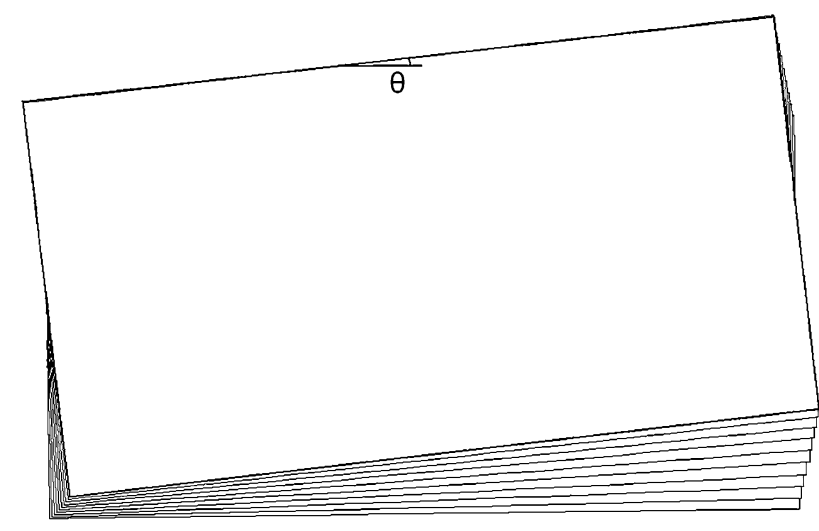

Fig. 8 Schematic displacement diagram

Table 8 Torsional irregularity coefficients and floor rotations for 10-story Type A structure

\begin{tabular}{lll}
\hline $\begin{array}{l}\text { Story } \\
\text { no. }\end{array}$ & $\begin{array}{l}\eta_{\mathrm{t}}\left(\delta_{\text {max }} /\right. \\
\left.\delta_{\text {avg }}\right)\end{array}$ & $\begin{array}{l}10^{3} \times \theta \\
\text { (radian) }\end{array}$ \\
\hline 10 & 1.528 & 2.206 \\
9 & 1.548 & 2.146 \\
8 & 1.565 & 2.018 \\
7 & 1.581 & 1.849 \\
6 & 1.597 & 1.628 \\
5 & 1.617 & 1.386 \\
4 & 1.638 & 1.110 \\
3 & 1.669 & 0.837 \\
2 & 1.705 & 0.543 \\
1 & 1.756 & 0.262 \\
Max & 1.756 & 2.206 \\
\hline
\end{tabular}

\section{Investigation of floor rotations}

In the seismic analyses presented in the preceding sections, it is assumed that the floors act as rigid diaphragms in their own planes and the structures undergo a displacement as shown schematically in Fig. 8. As can be seen in the figure, all stories undergo a rotation as well as displacements in two directions. In the following, the structure groups with 5 , 6, and 7 axes will be considered in turn and these rotations will be examined.

Structure group with five axes

As an illustrative example of structures with five axes, torsional irregularity coefficients $\eta_{\mathrm{t}}$ and floor rotations $\theta$ of the 10-story Type A structure are shown in Table 8 . Enlarged $\delta$ floor displacements are also shown schematically in Fig. 9. As can be seen by inspecting both Table 8 and Fig. 9, floor rotation angles significantly increase upwards, whereas the torsional irregularity coefficients decrease. It may be concluded that torsional irregularity coefficients $\eta_{\mathrm{t}}$ do not represent the torsional behavior accurately.

\section{All structure types with five axes}

Maximum rotation angles for all structure types with five axes are shown in Table 9. Maximum values at each row are shown with bold numerals. Interpretation of the results will be presented in a separate section.

Structure groups with six and seven axes

Similar observations were made for structures with six and seven axes by Ozmen et al. (2012). Maximum rotation angles for all structure types with those axes are shown in Tables 10 and 11, respectively.

Evaluation of floor rotations

Maximum floor rotations resulting from the seismic analyses of 96 structures have been presented in Tables 9, 10, and 11 and represented graphically in Figs. 10, 11, and 12, respectively.

It is observed that

(a) Maximum irregularity for all types occurs for 10-story structures,

(b) Maximum irregularity occurs for Type A structures.

It is seen that these observations are quite contradictory with those obtained for torsional irregularity coefficients in Section 4.4. Scattering of floor rotations $\theta$ with respect to torsional irregularity coefficients $\eta_{\mathrm{t}}$ is shown in Fig. 13. It is clearly seen that floor rotations which may be considered as being the real indicator of the torsional behavior are far from being compatible with the torsional irregularity coefficients. In fact, it can be said that these quantities are inversely proportional to each other. Examination of the above-mentioned observations yields the following conclusions:

- Torsional irregularity coefficients as defined in the regulations do not represent the torsional characteristics of the structures realistically,

- Code definitions of torsional irregularity coefficients should be completely amended.

\section{A new torsional irregularity definition proposal}

It is asserted in the preceding sections that the torsional behavior of structures is represented more realistically by 
Fig. 9 Floor displacement diagrams

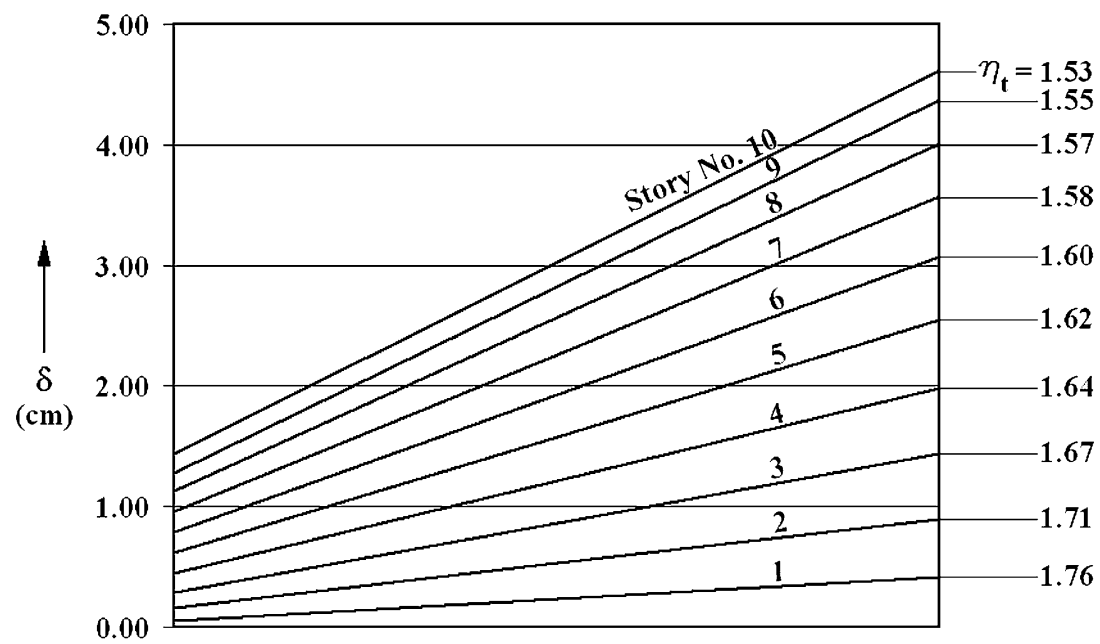

Table 9 Maximum floor rotations for structures with 5 axes

\begin{tabular}{lllll}
\hline \multirow{2}{*}{ Number of stories } & \multicolumn{4}{l}{ Structure type } \\
\cline { 2 - 5 } & $\mathrm{A}$ & $\mathrm{B}$ & $\mathrm{C}$ & $\mathrm{D}$ \\
\hline 1 & $\mathbf{0 . 1 0 6}$ & 0.075 & 0.094 & 0.042 \\
2 & $\mathbf{0 . 2 6 8}$ & 0.211 & 0.237 & 0.121 \\
4 & $\mathbf{0 . 8 3 4}$ & 0.727 & 0.745 & 0.436 \\
6 & $\mathbf{1 . 5 4 4}$ & 1.405 & 1.350 & 0.863 \\
8 & $\mathbf{1 . 8 9 3}$ & 1.782 & 1.626 & 1.130 \\
10 & $\mathbf{2 . 2 0 6}$ & 2.180 & 1.859 & 1.395 \\
\hline
\end{tabular}

Table 10 Maximum floor rotations for structures with 6 axes

\begin{tabular}{lllllll}
\hline \multirow{2}{*}{ Number of stories } & \multicolumn{6}{l}{ Structure type } \\
\cline { 2 - 7 } & A & B & C & D & E & F \\
\hline 1 & $\mathbf{0 . 0 9 9}$ & 0.058 & 0.097 & 0.063 & 0.061 & 0.014 \\
2 & $\mathbf{0 . 2 4 4}$ & 0.214 & 0.238 & 0.168 & 0.148 & 0.032 \\
4 & $\mathbf{0 . 7 4 9}$ & 0.705 & 0.736 & 0.573 & 0.455 & 0.151 \\
6 & $\mathbf{1 . 3 7 5}$ & 1.333 & 1.323 & 1.084 & 0.818 & 0.341 \\
8 & $\mathbf{1 . 6 7 0}$ & 1.657 & 1.573 & 1.354 & 1.003 & 0.511 \\
10 & $\mathbf{1 . 9 3 8}$ & 1.910 & 1.786 & 1.611 & 1.189 & 0.713 \\
\hline
\end{tabular}

Table 11 Maximum floor rotations for structures with 7 axes

\begin{tabular}{lllllll}
\hline \multirow{2}{*}{ Number of stories } & \multicolumn{6}{l}{ Structure type } \\
\cline { 2 - 7 } & A & B & C & D & E & F \\
\hline 1 & $\mathbf{0 . 0 9 4}$ & 0.082 & 0.093 & 0.072 & 0.077 & 0.041 \\
2 & $\mathbf{0 . 2 2 6}$ & 0.206 & 0.167 & 0.185 & 0.182 & 0.106 \\
4 & $\mathbf{0 . 6 6 3}$ & 0.637 & 0.651 & 0.582 & 0.531 & 0.345 \\
6 & $\mathbf{1 . 1 7 5}$ & 1.173 & 1.172 & 1.065 & 0.923 & 0.649 \\
8 & $\mathbf{1 . 4 3 0}$ & 1.407 & 1.376 & 1.293 & 1.085 & 0.825 \\
10 & $\mathbf{1 . 6 2 2}$ & 1.600 & 1.553 & 1.511 & 1.239 & 1.010 \\
\hline
\end{tabular}

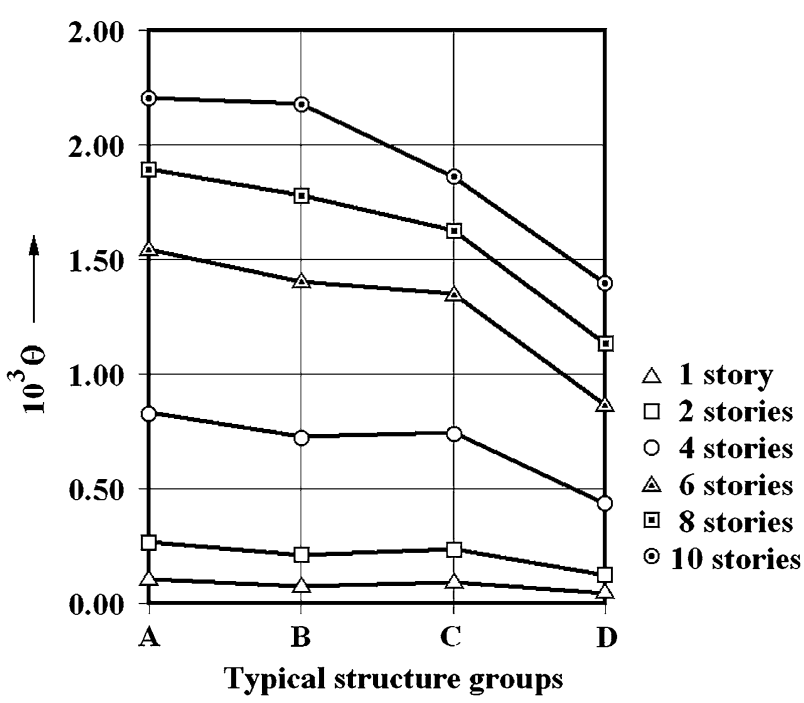

Fig. 10 Variation of floor rotations for structures with 5 axes

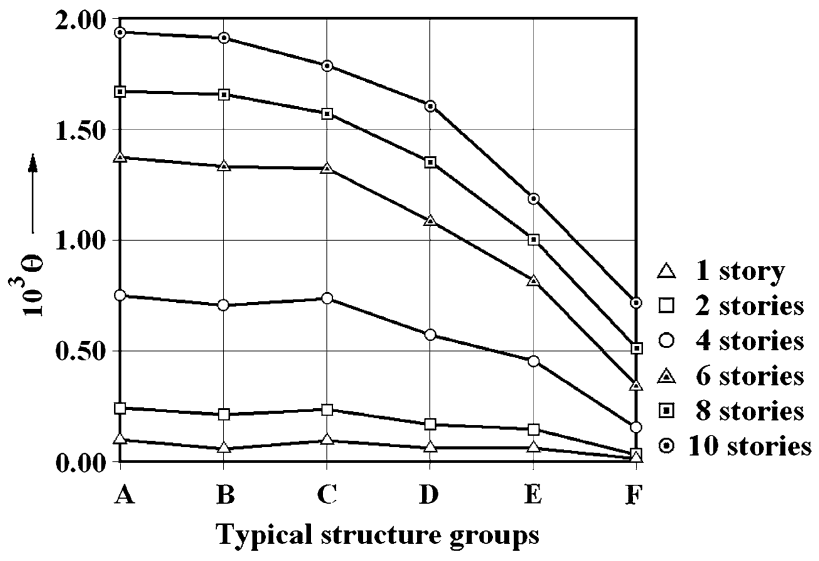

Fig. 11 Variation of floor rotations for structures with 6 axes 


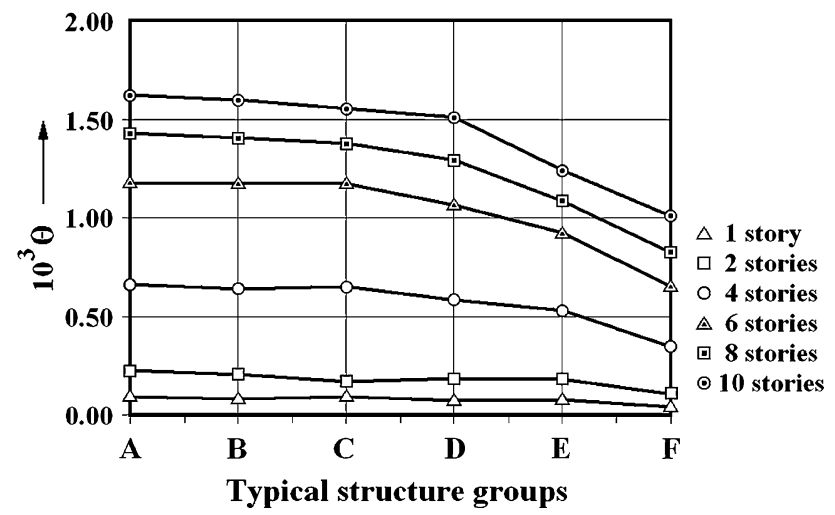

Fig. 12 Variation of floor rotations for structures with 7 axes

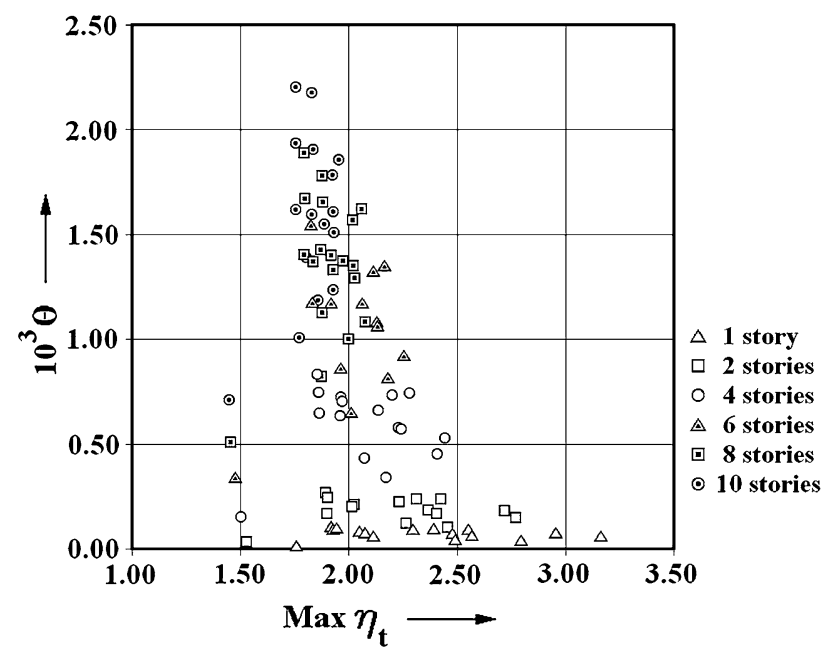

Fig. 13 Scattering of floor rotations with respect to torsional irregularity coefficients

rotations $\theta$ of rigid floors. Hence, the new definition for torsional irregularity coefficient is proposed as

$\eta_{\mathrm{ti}}=K\left|\theta_{\mathrm{i}}\right|$

where $\theta_{\mathrm{i}}$ denotes the rotation of the ith floor in radians. Considering the structures inspected in this study, a preliminary value for the coefficient $K$ may be recommended as

$K=1,500$

It must be considered natural to impose an upper bound for floor rotations similar to the drift limits existing in the regulations. An appropriate limitation for floor rotations is proposed as

$\left|\theta_{\mathrm{i}}\right| \leq 1.5 \times 10^{-3}$

It must be noted that this proposal is only provisional. An amendment of the definition for torsional irregularity coefficient seems to be a necessity but should be determined using further comprehensive investigations on the subject.American Society of Civil Engineers

\section{Conclusions}

In this study a parametric investigation is performed on six types of typical structures by considering different shear wall positions and story numbers and on the derived structure groups with varying axis number. Findings on lateral load analyses are evaluated and the following conclusions are summarized:

- For all the investigated structures, torsional irregularity coefficients increase as the story numbers decrease, i.e., maximum irregularity coefficients occur for singlestory structures.

- Floor rotations increase in proportion to the story numbers, i.e., maximum floor rotations occur for highest story numbers.

- Torsional irregularity coefficients reach maximum values when the shear walls are placed as close as possible to the centers of mass without coinciding them.

- On the contrary as it is expected, it can be seen that when the center of rigidity approaches to the center of mass, torsional irregularity coefficients increase due to decreasing torsional rigidity of structure.

- Floor rotations attain their maximum values for the structures where the walls are in farthest positions from the centers of mass.

- It is seen that the results obtained for torsional irregularity coefficients and floor rotations are quite contradictory.

- Since the floor rotations may be considered as the real representative of the torsional behavior, torsional irregularity coefficients as defined in the regulations should be completely amended.

- A provisional new definition for torsional irregularity coefficient is proposed.

Open Access This article is distributed under the terms of the Creative Commons Attribution License which permits any use, distribution, and reproduction in any medium, provided the original author(s) and the source are credited.

\section{References}

American Society of Civil Engineers (2005) ASCE 7-05, minimum design loads for buildings and other structures, p 420

American Society of Civil Engineers (2010) ASCE 7-10, minimum design loads for buildings and other structures, $\mathrm{p} 658$

Bosco M, Marino E, Rossi PP (2004) Limits of application of simplified design procedures to non-regular asymmetric 
buildings. 13th World conference on earthquake engineering, Paper No. 886

Comité Européen de Normalisation (CEN) Eurocode 8 (2004) Design of structures for earthquake resistance. Part 1: general rules, seismic actions and rules for buildings. Brussels (Belgium). The European Standard EN 1998-1:2004

Cosenza E, Manfredi G, Realfonzo R (2000) Torsional effects and regularity conditions in $\mathrm{RC}$ buildings. 12th World conference on earthquake engineering, Auckland, New Zealand, 2000

Demir A, Demir DD, Erdem RT, Bagci M (2010) Torsional irregularity effects of local site classes in multiple storey structures. Int J Res Rev Appl Sci: 258-262

Dogangun A, Livaoglu R (2006) Comparison of seismic analysis methods for multistory buildings. First European conference on earthquake engineering and seismology, Geneva, Switzerland, 3-8 September, Paper No. 13142006

Duan XN, Chandler AM (1997) An optimized procedure for seismic design of torsionally unbalanced structures. Earthquake Eng Struct Dynam 26(7):737-757

International Building Code (2006) IBC06, international code council (ICC), USA

Jeong SH, Elnashai AS (2004) Analytical and experimental seismic assessment of irregular RC buildings. 13th World conference on earthquake engineering, Vancouver, B.C., Canada, Paper No. 1132004

Jeong SH, Elnashai AS (2006) New three-dimensional damage index for RC buildings with planar irregularities. J Struct Eng ASCE 132(9):1482-1490

Jinjie M, Qingxuan S, Qi Z (2008) Method of performance based seismic evaluation for irregular plane reinforced concrete frame structures. 14th World conference on earthquake engineering, Beijing, 12-17 Oct 2008

Mahdi T, Gharaie VS (2011) Plan irregular RC frames: comparison of pushover with nonlinear dynamic analysis. Asian J Civil Eng Build Housing 12(6):679-690

Ozhendekci N, Polat Z (2008) Torsional irregularity of buildings. 14th World conference on earthquake engineering, Beijing, Oct $12-172008$

Ozmen G (2002) Structural aspects of torsional irregularity. 5th International congress on advances in civil engineering, Istanbul

Ozmen G (2004) Excessive torsional irregularity in multi-storey structures. Teknik Dergi Digest 15(1):3331

Ozmen G, Girgin K, Durgun Y (2012) Torsional irregularity in multistory structures. www.yapistatigi.itu.edu.tr/raporlar/raporlar.html

Penelis GG, Kappos AJ (2002) 3D pushover analysis: the issue of torsion. 12th European conference on earthquake engineering paper reference: 015

Tezcan SS, Alhan C (2001) Parametric analysis of irregular structures under seismic loading according to the new Turkish Earthquake Code. Eng Struct 23:600-609

Turkish Earthquake Code (2007) TEC2007, Specification for buildings to be built in seismic zones, 2007. Ministry of public works and settlement, government of Republic of Turkey, Turkey

Uniform Building Code (1997) UBC97, Structural engineering design provisions. International conference of building officials, Whittier, California, 1997

Zheng N, Yang Z, Shi C, Chang Z (2004) Analysis of criterion for torsional irregularity of seismic structures, 13th World conference on earthquake engineering, Vancouver, B.C., Canada, 1-6Aug, Paper No.1465 2004 